\title{
Atividade Neuroprotetora da Minociclina na Isquemia Cerebral: Revisão Sistemática
}

\author{
Neuroprotective Activity of Minocycline in Cerebral Ischemia: \\ Systematic Review
}

Recebido em: $17 / 02 / 2019$ Aceito em: $\quad 18 / 09 / 2019$
Jean Pierre de Oliveira ALENCAR ${ }^{1}$; Gustavo de Oliveira ALENCAR ${ }^{1}$; Iri Sandro Pampolha LIMA ${ }^{2}$ ${ }^{1}$ Faculdade de Juazeiro do Norte, FJN. Rua São Francisco, 1224, Bairro São Miguel, CEP 63010-475. Juazeiro do Norte, Ceará, Brasil. ${ }^{2}$ Departamento de Medicina, Universidade Federal do Cariri,UFCA. Rua Divino Salvador, 284, Bairro Centro, Barbalha, CEP 63180000. Cariri, Ceará, Brasil E-mail: jean.p.nerd@hotmail.com

\section{ABSTRACT:}

Stroke is caused by interruption of cerebral blood flow and may be of ischemic genesis. The subtypes are determined according to the origin, being: atherosclerosis of large arteries, cardioembolism, occlusion of small arteries, of other determined origins and unknown origin. The pharmacological treatment is the Tissue Plasminogen Activator, of narrow therapeutic window. Minocycline can cross the blood-brain barrier, acting on neuronal loss, becoming a neuroprotective potential of high applicability and specificity, blocking cellular groups responsible for the inflammatory and degenerative process. The objective was carry on a systematic review. The used, with the descriptors: minociclina/neuroproteção and minocycline/ neuroprotection, only sevem studies were selected, published between 2014 and 2018 available in full for free. Minocycline correlates with inhibition of NF- $\mathrm{KB}$ in neurons, antioxidant, has anti-apoptotic effect, improvement in tissue damage, functional recovery in animals, involvement with MCP1P1, and correlation with factor factors CREB, pCREB, and BDNF. The ability of neuroprotection obtained through minocycline treatment in ischemic models is remarkable. This promising therapy is definitively proven,

Keywords: Activity. Ischemia. Minocycline. Neuroprotection.

\section{RESUMO}

O acidente vascular cerebral é causado pela interrupção do fluxo sanguíneo cerebral, podendo ser de gênese isquêmica. Os subtipos são determinados conforme a origem, podendo ser: aterosclerose de grandes artérias, cardioembolismo, oclusão de pequenas artérias, de outras origens determinadas e de origem desconhecida. O tratamento farmacológico é o Ativador de Plasminogenio Tecidual, de estreita janela terapêutica. A minociclina é capaz de atravessar a barreira hematoencefálica, atuando na perda neuronal, sendo um potencial neuroprotetor de grande aplicabilidade e especificidade, bloqueando grupos celulares responsáveis pelo processo inflamatório e degenerativo. O objetivo foi realizar uma revisão sistemática de caráter qualitativo. As bases de dados consultadas foram: MEDLINE), PubMed e SciELO, com os descritores: minociclina/neuroproteção e minocycline/neuroprotection, Apenas sete estudos foram selecionados por meio do protocolo de pesquisa, publicados entre 2014 e 2018 e disponíveis na íntegra gratuitamente. Minociclina possui relação com a inibição de NF- $\kappa \mathrm{B}$ nos neurônios, efeito antioxidante, antiapoptótico, melhora no dano tecidual, recuperação funcional em animais, envolvimento com MCP1P1 e correlação com fatores os fatores CREB, pCREB, e BDNF. É notável a capacidade de neuroproteção obtida por meio do tratamento com minociclina em modelos isquêmicos.

Palavras-chave: Atividade. Isquemia. Minociclina. Neuroproteção. 


\section{INTRODUÇÃO}

O acidente vascular cerebral (AVC) é causado pela interrupção do fluxo sanguíneo cerebral, podendo ser de gênese hemorrágica ou isquêmica. Dessa forma, o suprimento de oxigênio e nutrientes é interrompido, causando danos ao tecido cerebral. Os sintomas mais comuns são: hemiplegia, confusão, disfasia, alterações visuais, dificuldade em andar, tontura, perda de equilíbrio ou coordenação, cefaleia sem causa conhecida e inconsciência (1). Quanto aos subtipos do acidente vascular cerebral isquêmico (AVCi), os mesmos são determinados conforme a origem, podendo ser: aterosclerose de grandes artérias, cardioembolismo, oclusão de pequenas artérias, de outras origens determinadas e de origem desconhecida (2).

No Brasil as estatísticas mostram uma prevalência de AVC. No município de Maringá, Paraná foi analisada a tendência de óbitos por AVC entre os anos de 2005 e 2015, sendo registradas 1843 mortes, das quais $52 \%$ foram indivíduos do sexo masculino e $74 \%$ em idosos (3).

Uma pesquisa realizada na cidade de Tubarão, Santa Catarina, visou a descrição do perfil de pacientes com AVCi atendidos em unidade hospitalar (4). Dentre os 57 avaliados, $56,1 \%$ eram homens, tendo como subtipos mais prevalentes o de origem cardioembólica e arterosclérotico de grandes vasos Em outro trabalho, em Rio Branco, Acre, foram descritas as características epidemiológicas e clínicas de pacientes acometidos por AVC. Dentre os 50 pacientes analisados, $74 \%$ foram diagnosticados com AVCi, 50\% eram idosos, $88 \%$ apresentavam hipertensão arterial e 70\% dos pacientes tiveram sequelas na fala (5).

Vários relatos de caso mostram possíveis sintomatologias relacionadas com o $\mathrm{AVC}$, dentre os quais o de uma paciente que apresentava processo isquêmico recorrente, oriundo de má formação arteriovenosa pulmonar. A mesma apresentava sintomatologia grave e lesão neuronal severa, sendo submetida a tratamento anticoagulante por tempo indeterminado (6).

Há também casos especiais, como o de duas pacientes jovens, residentes na República Checa. A primeira apresentava obesidade e Síndrome de
Alport e foi diagnosticada com isquemia cerebral, posteriormente agravada com elevação da pressão intracraniana. A segunda, portadora da Síndrome de Lippel-Trenaunay, apresentou transtorno de consciência, hemiparesia, afasia e anisocoria, e dois processos isquêmicos cerebrais seguidos foram detectados. Mesmo com trombectomia mecânica e intervenção cirúrgica, a mesma apresentou hemiparesia direita grave com lenta recuperação (7).

O acidente vascular cerebral isquêmico é a principal causa de incapacidade em longo prazo e impõe um encargo financeiro significativo tanto para o indivíduo quanto para a sociedade (8). O tratamento farmacológico aprovado para o $\mathrm{AVCi}$, é o Ativador de Plasminogenio Tecidual (tPA), que deve ser aplicado nas primeiras 3-4 horas, com estreita janela terapêutica (9-11).

A minociclina consiste em um antibiótico bacteriostático de amplo espectro e de longa ação, durando 16-18 horas. A absorção da mesma após administração oral é de 95 a 100\%, não sofrendo interferência por alimentos ricos em cátions multivalentes, meio alcalino, antiácidos e laticínios. A penetração no microrganismo se dá por meio da difusão passiva e em parte por transporte dependente de energia, dessa forma ligando-se reversivelmente subunidade $30 \mathrm{~S}$ do ribossomo bacteriano, impedindo a adição de aminoácidos ao peptídeo em crescimento. Esse antibiótico possui atividade contra diversas bactérias gram-positivas, gram-negativas, alguns tipos de aeróbias, riquetsias, clamídias, mioplasmas e, em especial, pode erradicar o estado de portador meningocócico (12).

Este antibiótico também é capaz de atravessar a barreira hematoencefálica, modulando a perda neuronal originária do acidente vascular cerebral isquêmico, dessa forma tornando-se um potencial neuroprotetor de grande aplicabilidade e especificidade no sistema nervoso central, bloqueando grupos celulares responsáveis pelo processo inflamatório e degenerativo (13-17).

Assim, o presente trabalho teve como objetivo avaliar a capacidade de neuroproteção da minociclina no contexto da isquemia cerebral por meio de revisão de trabalhos disponíveis na literatura científica, abordando aspectos farmacodinâmicos e discutindo os artigos selecionados. 


\section{MÉTODO}

Tratou-se de uma revisão sistemática de caráter qualitativo, na qual foi buscada a produção científica relacionada ao acidente vascular cerebral isquêmico e o uso da minociclina como neuroprotetor, sendo realizada no mês de dezembro de 2018. As bases de dados utilizadas foram: MEDLINE (Medical Literature Analysis and Retrieval System Online), PubMed (Public Medline) e SciELO (Scientific Electronic Library Online). Os descritores aplicados foram: minociclina/neuroproteção e minocycline/neuroprotection. O período considerado foi 2014 a 2018, disponíveis na íntegra gratuitamente, conforme esquematizado na Figura 1. Para a análise das publicações foi considerado como critério de inclusão trabalhos envolvendo estudos com modelos experimentais associados ou não a agentes neurotóxicos, investigações de vias farmacodinâmicas responsáveis pela neuroproteção, comparativos entre a neuroproteção mediada pela minociclina e outras metodologias.

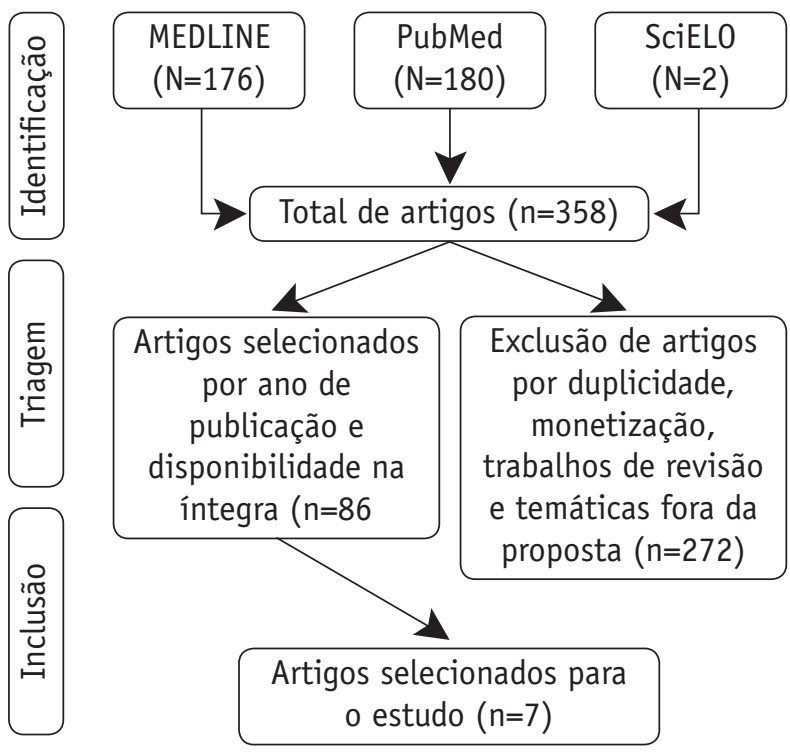

Figura 1. Esquematização adotada para seleção do estudo sobre minociclina.

\section{RESULTADOS E DISCUSSÃO}

Dos 344 estudos obtidos, apenas 7 foram selecionados, considerando o protocolo de pesquisa, dentre os quais três são brasileiros, um indiano e três chineses, sendo o último em parceria com os Estados Unidos, conforme Quadro 1. Após análise, todos reafirmaram a capacidade de neuroproteção da minociclina, aprofundando a versatilidade e relacionando os aspectos farmacodinâmicos envolvidos. Foram excluídos trabalhos duplicados em banco de dados, manuscritos de autores, hipoperfusão cerebral crônica, artigos de revisão e propostas fora da temática: isquemia de retina, lesão de medula espinhal, neuroproteção após uso do midazolam, efeitos psicóticos, recuperação cognitiva mediante exposição ao isoflurano e cirúrgica. O AVCi está entre as principais causas de incapacidade, devido à interrupção do fluxo sanguíneo. O córtex motor é uma das principais áreas do cérebro responsáveis pelas manifestações clínicas, nas quais $42 \%$ dos sobreviventes apresentaram deficiências motoras. A isquemia focal na região do córtex motor em ratos é capaz de reduzir atividade locomotora e induzir severas deficiências de coordenação, equilíbrio e aprendizagem motora. Esses eventos podem ser resultados da expansão do núcleo isquêmico e das áreas de penumbra após o derrame, juntamente com o recrutamento, ativação de astrócitos e células microgliais, desencadeada pela ativação de mediadores pró-inflamatórios e fatores quimiotáticos. Essas alterações são acompanhadas pela excitotoxicidade glutamatérgica, ativação de enzimas cálcio-dependentes e pela ação de xantina oxidase e NADPH oxidase, que produzem espécies reativas de oxigênio (NOS), exarcebando o estresse oxidativo no córtex cerebral. 
Quadro 1. Estudos selecionados envolvendo à neuroproteção da minociclina na isquemia cerebral (2014-2018).

\begin{tabular}{|c|c|c|}
\hline Autores / País & Objetivo & Metodologia \\
\hline $\begin{array}{l}\text { Alam e cols (2016), } \\
\text { Índia (18) }\end{array}$ & $\begin{array}{l}\text { Formular e elucidar o meca- } \\
\text { nismo da imunomodulação } \\
\text { responsável pela melhora da } \\
\text { plasticidade sináptica, rea- } \\
\text { bilitação e neurorestauração } \\
\text { no processo isquêmico. }\end{array}$ & $\begin{array}{l}\text { Foi utilizada uma abordagem de biologia de sistemas por meio } \\
\text { da formulação de interações cinéticas celulares e equações } \\
\text { químicas diferenciais. } 0 \text { mecanismo foi deduzido com base na } \\
\text { regulação dos genes e proteínas relacionadas ao NF- } \mathrm{KB} \text {. Na sim- } \\
\text { ulação foram utilizadas doses de } 4,5 \mathrm{mg} / \mathrm{kg} \text {. }\end{array}$ \\
\hline
\end{tabular}

Fontes-Júnior e cols, Investigar o potencial efeito (2016), Brasil (13) neuroprotetor do tratamento com minociclina em ratos isquêmicos cronicamente intoxicados com etanol desde a adolescência, com foco na análise da ativação da glia e do estresse oxidativo..

Jin e cols (2015), Determinar se a proteína China/Estados Uni- 1 induzida por proteína dos (19) quimiotática de monócito (MCPIP1), está envolvida na neuroproteção cerebral responsável pela minociclina no modelo de isquemia cerebral e elucidar os mecanismos envolvidos

Min e cols 2017, Chi- Examinar as respostas inna, (20) flamatórias periféricas ou cerebrais frente à hipóxia sistêmica e quais os papéis que elas desempenharam na hipomielinização cognitiva e da substância branca.

Oliveira e cols Investigar se a exposição (2014), Brasil (15) crônica ao etanol durante a adolescência potencializa as deficiências motoras e 0 dano histológico induzido pela isquemia focal em ratas e se esses efeitos podem ser reduzidos pela minociclina.

Souza e cols (2017), Comparar os efeitos do traBrasil (21) tamento com minociclina e 0 transplante de células mononucleares da medula óssea após infarto, avaliando perda de neurônios, ativação da microglia, apoptose e recuperação.

Zhao e cols (2015), Observar a expressão de China (22)

CREB, CREB fosforilada (pCREB) e BDNF no hipocampo da isquemia cerebral em ratos e explorar o mecanismo neuroprotetor de minociclina, juntamente com os efeitos na aprendizagem, memória e recuperação funcional.
60 ratas Wistar divididas aleatoriamente em seis grupos receberam água destilada por via oral ou etanol uma vez ao dia. A isquemia focal foi induzida por microinjeção de endotelina.

A minociclina foi administrada em quatro doses de $50 \mathrm{mg} / \mathrm{kg}$ a cada 12 horas seguido de cinco doses de $25 \mathrm{mg} / \mathrm{kg}$ a cada 24 horas. Eensaios comportamentais, testes bioquímicos, análise de peroxidação lipídica e níveis de nitrito por espectrofotometria, avaliações histológicas e imunohistoquímicas. Os resultados foram analisados estatisticamente.

A isquemia cerebral foi induzida por oclusão da artéria cerebral média em ratos machos e camundongos com ausência de MCPIP1. Doze horas antes da isquemia ou 2 horas após 0 acidente vascular cerebral, foram injectados $90 \mathrm{mg} / \mathrm{kg}$ de minociclina. Posteriormente, os foram injetados $90 \mathrm{mg} / \mathrm{kg}$ duas vezes ao dia, após isquemia até 0 sacrifício. A transcrição e expressão do gene MCPIP1 foram monitorizadas por PCR Western blot e imuno-histoquimíca. Os resultados neurocomportamentais, voa sinalização de NF- $\kappa$ B foram avaliados. Os dados foram analisados estatisticamente.

Foram utilizados filhotes de ratos para simular a hipóxia sistêmica. Uma dose inicial de minociclina $45 \mathrm{mg} / \mathrm{kg}$ foi injetada $2 \mathrm{~h}$ após o término da exposição à hipóxia, seguido por meia dose $(22,5 \mathrm{mg} / \mathrm{kg})$ tratamento com minociclina por seis dias consecutivos diariamente. 0 grupo controle recebeu salina. As células neurais foram isoladas, com seguida remoção da mielina e aplicação em citometria de fluxo. Também foram realizados testes comportamentais, aprendizagem de referência espacial, memória, ressonância magnética e ensaios imunohistoquími$\cos$. Os resultados foram analisados estatisticamente.

60 ratas adolecentes Wistar foram alocadas em grupos para análises. Com isso, foi iniciado o tratamento com minociclina após $2 \mathrm{~h}$ após a isquemia, em dosagens de $50 \mathrm{mg} / \mathrm{kg}$ durante 2 dias e subsequentemente em doses de $25 \mathrm{mg} / \mathrm{kg}$ até o sétimo dia. Posteriormente houve avaliação locomotora, imunohistoquimica e histopatológica. Os resultados foram submetidos à análise estatística.

Ratos adultos Wistar foram submetidos a isquemia e divididos em grupos. A minociclina foi administrada duas vezes ao dia em doses de $50 \mathrm{mg} / \mathrm{kg}$ por dois dias. Doses subsequentes de $25 \mathrm{mg} /$ $\mathrm{kg}$ foram administradas durante 4 dias. As células mononucleares da medula óssea foram isoladas do fêmur e tíbia, quantificados e administrados a uma concentração de 106 celulas/ $\mathrm{mL}$.Houve avaliação comportamental, histológica, imunohistoquímica. 0 s resultados foram analisados estatisticamente.

0 modelo animal foi estabelecido por oclusão das artérias carótidas. 0 comportamento foi avaliado. A minociclina foi administrada em doses de $50 \mathrm{mg} / \mathrm{kg} /$ dia e CREB e pCREB foram examinados por Western blotting, reação em cadeia da polimerase de transcrição reversa e imuno-histoquímica. 0 BDNF foi medido por imuno-histoquímica e Western blotting. Os resultados foram analisados estatisticamente. lumes de infarto e as citocinas pró-inflamatórias no cérebro e

\section{Resultados}

A simulação mostrou que o mecanismo está envolvido na inibição de NF-KB em neurônios e foi correlacionado com a

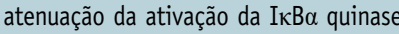
(IKK), fosforilação, degradação de IкB $\alpha$, fosforilação e translocação de p65 e regulação do TNF- $\alpha$.

0 estudo evidência que 0 álcool pode exacerbar os efeitos deletérios da isquemia cerebral.

A minociclina apresentou afeito antioxidante significativo e neutralizou 0 comprometimento motor em ratos submetidos apenas a isquemia. Ratos com isquemia associada a intoxicação alcoólica crônica apresentaram resultados parcialmente eficaz.

A indução de MCPIP1 está envolvida na neuroproteção induzida por minociclina de lesão cerebral isquêmica. Houve ação neuroprotetora, redução do tamanho do enfarte, melhora no quadro neurológico e seguida pela indução dos níveis de MCPIP1 em neurônios e microgla.

Hipóxia sistêmica induziu déficits cognitivos e hipomielinização.

A inflamação periférica está envolvida na neuroinflamação e ativação leucocitária circulatória.

0 efeito benéfico da minociclina sobre a lesão cerebral envolve seu papel nos leucócitos e na liberação de citocinas no sangue periférico.

A exposição do etanol durante a adolescência exacerba os comprometimentos associados à isquemia focal do córtex motor.

0 tratamento com minociclina melhora 0 dano tecidual e a recuperação funcional em ratas isquêmicas e expostas a etanol.

0 tratamento com minociclina apresentou resultados semelhantes quanto à redução da perda neuronal, na recuperação funcional e na ação antiinflamatória. Quanto à ativação microglial e redução das células apoptóticas, 0 transplante celular apresentou melhores resultados.

A minociclina atenuou o comprometimento cognitivo e aumentou CREB, PCREB e BDNF no hipocampo, protagonizando diretamente a reorganização e o reparo estrutural da região. 
Outros mecanismos envolvidos nesse processo estão relacionados com o aumento da atividade da fosfolipase A2, levando à oxidação, peroxidação e epoxidação de ácidos graxos, oxidação da CIP2E1, déficits nos mecanismos de remoção de espécies reativas, e depleção de antioxidantes endógenos $(9,10,13)$

A ativação da microglia contribui para a fisiopatologia do acidente vascular cerebral, gerando prejuízos ao tecido nervoso. No entanto, a microglia também atua de forma benéfica, contribuindo para as ações do processo inflamatório. A ativação associada à neuroinflamação é tipo $\mathrm{M} 1$, diferentemente da ativação microglial tipo M2, associada à neuroproteção. A ativação M1 aumenta a atividade do $\mathrm{NF} \kappa \mathrm{B}$, com uma consequente expressão aumentada de TNF- $\alpha$, interleucina- $1 \beta$, IFN- $\gamma$, COX-2, prostaglandinas e NOS $(13,15)$. O TNF- $\alpha$ atua como uma citocina pró-inflamatória, capaz de afetar o sono e o desenvolvimento embrionário. $\mathrm{Na}$ lesão cerebral, ocorre liberação pela micróglia, astrócitos e neurônios. A interleucina- $1 \beta$ é uma citocina produzida por macrófagos ativados, sendo um mediador inflamatório envolvido na apoptose celular, proliferação e diferenciação (23).

A reperfusão com o tPA continua sendo o tratamento de primeira escolha para o AVCi e o único aprovado pela FDA (Food and Drug Administration). No entanto, quando administrado além da janela terapêutica, ocorrem efeitos danosos resultantes do medicamento, como a transformação hemorrágica. Com isso há necessidade novas abordagens que reduzam os riscos e flexibilizem o manejo $(24,25)$. O tratamento com minociclina parece apresentar eficácia na prevenção e na reversão de alterações comportamentais e parâmetros oxidativos em modelos experimentais de neuropatologias agudas em roedores, favorecendo o uso da droga com baixos efeitos colaterais (13). A inibição da ativação microglial é considerada um importante aspecto farmacodinâmico, atuando também como protetor mitocondrial e um antioxidante, por meio da diminuição da liberação de espécies reativas de oxigênio pela célula, apresentando eficácia semelhante ao alfa-tocoferol $(15,21)$.

A minociclina também é capaz de reduzir a expressão de $\mathrm{NF} \kappa \mathrm{B}$, interleucina-1beta (IL-1 $\beta$ ), reduzir a expressão de ciclooxigenase 2 (COX-2) e prostaglandina E2 em áreas isquêmicas cerebrais, agir por mecanismos anti-apoptóticos, interferindo no citocromo $\mathrm{C}$ mitocondrial e outros fatores no citoplasma, impedindo a ativação de caspase-3 e 9 $(13,15,21)$. Além disso, a minociclina diminui a área da lesão e a perda neuronal, inibindo a atividade da metaloproteinase de matriz 9 (MMP-9), endopeptidase dependente de zinco liberada pelos neurônios. Esta enzima contribui para agravar o processo de excitotoxicidade, danos e morte celular, afetando a integridade da barreira hematoencefálica. Também é capaz de proteger o neurônio de processos oxidativos e indução excitotóxica do N-metil-D-aspartato (NMDA) reduzindo o influxo e a absorção de cálcio pelas mitocôndrias $(13,21,26)$. Resultados de ensaios clínicos mostraram que a minociclina oral e intravenosa, aplicada em tempo e dosagens específicas, é capaz de melhoras clinicas significativas, evidenciando segurança, eficácia e viabilidade do tratamento (11).

A exposição do sistema nervoso central ao etanol é capaz de causar efeitos devastadores, em que a morte neuronal acompanhada da ativação microglial e neuroinflamação mostram-se evidentes (27). Devido ao fato de o alcoolismo, por tratar-se de um problema de saúde pública e afetar indivíduos de maneira psicossomática, há estudos que avaliam a associação do etanol com a isquemia cerebral, mostrando a ocorrência de exacerbação dos danos resultantes principalmente no lobo frontal, sistema límbico e cerebelo (28). Com isso, foi avaliado o potencial dano neurológico do etanol em ratas fêmeas submetidas à isquemia induzida e se a minociclina seria capaz de atenuar tais alterações. $\mathrm{O}$ etanol, administrado cronicamente durante a adolescência, foi capaz de exacerbar os efeitos oriundos da isquemia focal induzida, causando danos motores e histológicos. A minociclina reduziu tais déficits, protegendo contra a perda de neurônios piramidais no córtex motor, sendo promissora para futuras aplicações em casos de acidentes vasculares cerebrais e até intoxicações alcoólicas (15).

Em estudo semelhante, com enfoque comportamental, na ativação das células da glia e no estresse oxidativo, também foi detectada alteração significativa da capacidade motora causada pelo uso crônico do álcool e elevado sinergismo quan- 
do associado com a isquemia cerebral (13). Após o tratamento com a minociclina na intoxicação alcoólica crônica, isquemia e sua associação, houve redução do comprometimento motor, redução no estresse oxidativo e da morte dos neurônios causada pela isquemia e parcial redução da peroxidação lipídica. Apesar da morte neuronal maior que $75 \%$ e a significativa redução das células no córtex motor, o tratamento foi suficiente para normalizar alguns parâmetros e prevenir parcialmente a morte neuronal, consistindo um efeito protetor significativo. Mesmos com os importantes resultados, os autores ainda sugeriram ajustes na dose, períodos mais longos de tratamento, ou o uso adicional de um antioxidante.

A terapia celular aplicada à isquemia cerebral está dentre as mais promissoras, com melhoras significativas nas funções neurológicas e na qualidade de vida (11). Estudos avaliaram a recuperação funcional e estrutural durante o acidente vascular cerebral com o uso de células da medula óssea (29). As células mononucleares da medula óssea são capazes de modular o ambiente patológico, diminuir a inflamação, aumentar a angiogênese por liberação fatores de crescimento e citocinas antiinflamatórias, promovendo considerável neuroproteção e recuperação funcional. A neuroproteção da minociclina foi comparada ao transplante de células da medula óssea mediante isquemia focal induzida. $\mathrm{O}$ tratamento com minociclina apresentou resultados semelhantes quanto à redução da perda neuronal, na recuperação funcional e na ação anti-inflamatória. Quanto a ativação microglial e redução das células apoptóticas, o transplante celular apresentou melhores resultados. Os dados sugeriram que tanto a minociclina quanto o transplante são promissoras abordagens terapêuticas (21). Também foi avaliada, em outro estudo, a terapia com células derivadas da medula óssea associadas à minociclina. Os resultados mostraram melhores índices neurológicos, menor área infartada e melhor recuperação neurológica na terapia combinada (30).

A microglia constitui cerca de $10 \%$ do total de células cerebrais, responsável pela apresentação de antígenos, fagocitose de detritos celulares e sensores de eventos patológicos. Essas células são encontradas no núcleo isquêmico de 1 a 2 dias após o infarto (31). Em trabalho realizado na Índia, utilizando modelos biológicos computadorizados, pesquisadores mostraram o mecanismo molecular responsável pela modulação de $\mathrm{NF}-\kappa \mathrm{B}$ por meio da minociclina, na qual foi inibida em neurônios e em células da glia, sendo correlacionada com redução da I $\kappa \mathrm{B} \alpha$ quinase (IKK), fosforilação e degra-

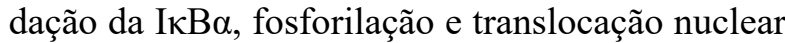
de p65 e redução da metaloproteinase de matriz 9 (MMP9). A inibição do NF-אB é mediada pela supressão da microglia M1 neurotoxica e ativação da micróglia M2 neuroprotetora (18,26,32).

No AVC agudo, a hipóxia inicia uma resposta neuroinflamatória com a produção de radicais livres, proteases, ruptura da barreira hematoencefálica e danos à mielina (33). Com isso, a capacidade de aprendizagem e déficits cognitivos de ratos neonatos submetidos à hipóxia sistêmica e ao tratamento com minociclina foi avaliada, no qual o grupo teste apresentou melhores resultados em relação ao controle, mesmo tratado após o dano (34). Nesse mesmo estudo também foi detectada inibição da resposta inflamatória, com redução nos níveis de fator de necrose tumoral (TNF- $\alpha$ ), efeito protetor contra anormalidades da bainha de mielina causada pela hipóxia, inibição da proliferação dos leucócitos e monócitos circulantes. Ratos espontaneamente hipertensos, que tiveram oclusão momentânea da artéria cerebral, receberam dosagens de minociclina. $\mathrm{O}$ resultado foi uma significativa redução da área infartada, melhora na perfusão sanguínea, redução na perda tecidual, redução de citocinas pró-inflamatórias e elevação de citocinas anti-inflamatórias, como TGF- $\beta$ e IL-10 (34).

A Proteína de Ligação AMP Cíclica com Elemento de Resposta (CREB) e o Fator Neurotrófico Derivado do Cérebro (BDNF) são moléculas responsáveis pela modulação do humor, comportamento e memória. O CREB pertencente à família dos fatores de transcrição de leucina, em que a fosforilação de CREB pode ser realizada por várias cascatas bioquímicas, sendo um componente para o pré-condicionamento isquêmico. Esse fator possui significativa importância na fisiopatologia do comprometimento cognitivo e crítico para a sobrevivência de neurônios após isquemia. O BDNF é uma neurotrofina pertence à família de fatores de reguladores de crescimento nervoso, secretada por neurônios e astrócitos na região centra do sistema 
nervoso. As neurotrofinas desempenham um papel crítico no desenvolvimento, excitabilidade e na plasticidade cerebral. O BDNF está fortemente relacionado às mudanças estruturais associadas à lesão e também como alvo terapêutico da lesão isquêmica cerebral, sendo um importante fato regenerativo. Foi analisada a expressão de CREB, CREB fosforilada (pCREB) e BDNF no hipocampo da isquemia cerebral em ratos e foi investigado o mecanismo neuroprotetor de minociclina. CREB, pCREB, e BDNF foram reprimidos no grupo modelo, e a minociclina atenuou o comprometimento cognitivo e aumentou CREB, pCREB e BDNF no hipocampo, protagonizando diretamente a reorganização e o reparo estrutural da região. A capacidade de minociclina para modular o comprometimento cognitivo pode ser de grande importância na seleção de agentes neuroprotetores $(22,23,35,36,37)$.

A Proteína Induzida por Proteína Quimiotática de Monócito 1 (MCPIP1), também conhecida como regnase-1, foi descoberta a partir da expressão em monócitos periféricos tratados com Proteína Quimiotática Monocitária 1 (MCP-1) (38). Estudos indicaram que a mesma tem quatro domínios: um domínio N-terminal (NTD), um domínio como o N-terminal da PilT (PIN), um domínio finger de zinco (ZF) e um domínio C-terminal (CTD), nos quais os domínios PIN e DTN atuam na atividade enzimática (39). O MCPIP1 inibe a ativação de macrófagos e a produção de citocinas inflamatórias, como o TNF $\alpha$, IL-1 $\beta$, IL-6, MCP-1 e as vias inflamatórias do NF-kB. Com isso, foi avaliado o envolvimento do MCPIP-1 com a neuroproteção mediada pela minociclina frente a isquemia cerebral. Foi mostrada uma significativa ação neuroprotetora, redução do tamanho do enfarte, melhora no quadro neurológico, seguida pela indução dos níveis de MCPIP1 em neurônios e microglia. Em indivíduos deficientes de MCPIP1, houve falha no tratamento com minociclina, apesentando elevados níveis de TNF $\alpha$, IL-1 $\beta$, IL-6 e MCP-1. A neuroproteção foi presente com a administração da minociclina antes e depois do quadro isquêmico e a MCPIP1 estava envolvida na inibição da via de si-

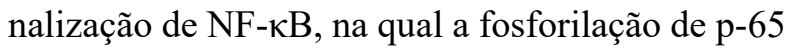
foi significativamente reduzida (19).

\section{CONCLUSÃO}

O AVCi permanece com um único tratamento aprovado. O reposicionamento de fármacos já utilizados na clínica para outras situações patológicas pode ser uma alternativa eficaz. Atualmente, o antibiótico minociclina tem sido estudado por sua atividade neuroprotetora em vários modelos experimentais de isquemia cerebral. Diante do exposto, é notável a capacidade de neuroproteção obtida por meio do tratamento com minociclina em modelos isquêmicos. É necessário que estudos clínicos em humanos sejam realizados, aprofundados e abertamente divulgados, para que tal promissora terapia esteja definitivamente comprovada e brevemente adentrada em protocolos clínicos para o tratamento de $\mathrm{AVCi}$, proporcionando assim melhor sobrevida desses pacientes.

\section{REFERÊNCIAS}

1. WHO. World Health Organization. Stroke Cerebrovascular Accident. Genebra: WHO, 2018. Disponível em: http://www.who.int/topics/cerebrovascular_accident/en/. Acesso em: 12 dez. 2018.

2. Chung J, Park SH, Kim N, Kim W, Park JH, Ko Y, Yang MH, Jang MS, Han M, Jung C, Kim JH, Oh CW, Bae H. Trial of ORG 10172 in Acute Stroke Treatment (TOAST) Classification and Vascular Territory of Ischemic Stroke Lesions Diagnosed by Diffusion-Weighted Imaging. J Am Heart Assoc. 2014;3(4):1-8. DOI: 10.1161/ JAHA.114.001119.
3. Araújo JP, Darcis JVV, Tomas ACV, Mello WA. Tendência da Mortalidade por Acidente Vascular Cerebral no Município de Maringá, Paraná entre os Anos de 2005 a 2015. Int J Cardiovasc. Sci. 2018;31(1):56-62. DOI: 10.5935/2359-4802.20170097.

4. Locatelli MC, Furlaneto AF, Cattaneo TN. Perfil epidemiológico dos pacientes com acidente vascular cerebral isquêmico atendidos em um hospital. Rev Soc Bras Clin Med. 2017;15(3):150-154.

5. Lima CMG, Silva HPW, Souza PAS, Amaral TLM, Prado PR. Características epidemiológicas e clínicas dos pacientes acometidos por acidente vascular cerebral. J Health Sci Inst. 2015;33(1): 45-49. 
6. Yang X, Liu M, Zhu Y, Zhang X, Gao S, Ni J. An overlooked cause in a patient with recurrent ischemic stroke: A case report. Medicine. 2018;97(13):1-3. DOI: 10.1097/ MD.0000000000010146.

7. Klucka J, Stourac P, Stoudek R, Toukalkova M, Harazim H, Kosinova M, Stouracova A, Mrlian A, Suk P, Malaska J. Ischemic stroke in paediatrics - narrative review of the literature and two cases. Biomed Pap Med Fac Univ Palacky Olomouc Czech Repub. 2017;161(1):24-30. DOI: $10.5507 / \mathrm{bp} .2016 .053$.

8. Kanyal N. The Science of Ischemic Stroke: Pathophysiology \& Pharmacological Treatment. IJPRR. 2015;4(10): 65-84.

9. Chaturvedi M, Kaczmarek L. MMP-9 Inhibition: a Therapeutic Strategy in Ischemic Stroke. Mol Neurobiol. 2013;49(1): 563-573. DOI: 10.1007/s12035-013-8538-z.

10. Sas A, Horváth L, Oláh C, Valikovics A. Review of Neuroinflammatory Mechanisms in Ischemic Stroke: Background and Therapeutic Approaches. Mechanisms Neuroinflamm. 2017;6:119-144. DOI: 10.5772/intechopen.69234.

11. Venkat, P Shen Y, Chopp M, Chen J. Cell-based and pharmacological neurorestorative therapies for ischemic stroke. Neuropharmacol. 2018;134: 310-322. DOI: 10.1016/j.neuropharm.2017.08.036.

12. Katzung BG, Trevor AJ. Farmacologia básica e clínica. $13^{\mathrm{a}}$ ed., Porto Alegre: AMGH, 2017.

13. Fontes-Júnior EA, Maia CSF, Fernandes LMP, Gomes-Leal W, Costa-Malaquias A, Lima RR, Prediger RD, Crespo-López ME. Chronic Alcohol Intoxication and Cortical Ischemia: Study of Their Comorbidity and the Protective Effects of Minocycline. Oxid Med Cell Longev. 2016;1-10. DOI: 10.1155/2016/1341453.

14. Liu Z, Fan Y, Won SJ, Neumann M, Hu D, Zhou L, Weinstein PR, Liu J. Chronic treatment with minocycline preserves adult new neurons and reduces functional impairment after focal cerebral ischemia. 2007;38:146-152. DOI: 10.1161/01.STR.0000251791.64910.cd.

15. Oliveira GB, Fontes Jr EA, Carvalho S, Silva JB, Fernandes LMP, Oliveira MCSP, Prediger RD, Gomes-Leal W, Lima RR, Maia CSF. Minocycline mitigates motor impairment sand cortical neuronal loss induced by focal ischemia in rats chronically exposed to ethanol during adolescence. Brain Res. 2014;1561:23-34. DOI: 10.1016/j. brainres.2014.03.005.

16. Yrjänheikki J, Tikka T, Keinänen R, Goldsteins G, Chan $\mathrm{PH}$, Koistinaho J. A tetracycline derivative, minocycline, reduces inflammation and protects against focal cerebral ischemia with a wide therapeutic window. Proc Natl Acad Sci USA. 1999;96 (23):13496-13500.
17. Yrjänheikki J, Keinänen R, Pellikka M, Hökfelt T, Koistinaho J. Tetracyclines inhibit microglial activation and are neuroprotective in global brain ischemia. Proc Natl Acad Sci USA. 1998;95 (26):15769-15774.

18. Alam MA, Rallabandi VPS, Roy PK. Systems biology of immunomodulation for Post-stroke neuroplasticity: Multimodal implications of pharmacotherapy and neurorehabilitation. Front Neurol. 2016;7 (94):1-16. DOI: 10.3389/ fneur.2016.00094.

19. Jin Z, Liang J, Wang J, Kolattukudy PE. MCP-induced protein 1 mediates the minocycline-induced neuroprotection against cerebral ischemia/reperfusion injury in vitro and in vivo. J Neuroinflammation. 2015;12 (39):1-12. DOI: 10.1186/s12974-015-0264-1.

20. Min Y, Li H, Xu K, Huang Y, Xioao J, Wang W, Li L, Yang T, Huang L, Jiang H, Wnag Q, Zhao M, Hua H, Mei R, Li F. Minocycline-suppression of early peripheral inflammation reduces hypoxia-induced neonatal brain injury. Front Neurosci. 2017; 11(511): 1-14 DOI: 10.3389/ fnins.2017.00511.

21. Souza CC, Silva MC, Lopes RT, Cardoso MM, Souza LL, Santos AG, Santos IR, Franco ECS, Gomes-Leal W. Comparative therapeutic effects of minocycline treatment and bone marrow mononuclear cell transplantation following striatal stroke. Oxid Med Cell Longev. 2017:116. DOI: 10.1155/2017/1976191.

22. Zhao Y, Xiao M, He W, Zhiyou C. Minocycline upregulates cyclic AMP response element binding protein and brain-derived neurotrophic factor in the hippocampus of cerebral ischemia rats and improves behavioral déficits. Neuropsychiatr Dis Treat. 2015;11:507-516. DOI: 10.2147/NDT.S73836.

23. Parry SM, Peeples ES. The impact of hypoxic-ischemic brain injury on stem cell mobilization, migration, adhesion, and proliferation. Neural Regen Res. 2018;13(7):11251135. DOI: 10.4103/1673-5374.235012.

24. Peña I, Borlongan C, Shen G, Davis W. Strategies to Extend Thrombolytic Time Window for Ischemic Stroke Treatment: An Unmet Clinical Need. J Stroke. 2017;19(1): 50-60. DOI: 10.5853/jos.2016.01515.

25. Knecht T, Story J, Liu J, Davis W, Borlongan CV, Peña IC. Adjunctive Therapy Approaches for Ischemic Stroke: Innovations to Expand Time Window of Treatment. Int J Mol Sci. 2017;18(12):1-18. DOI:10.3390/ijms18122756.

26. Shultz RB, Zhong Y. Minocycline targets multiple secondary injury mechanisms in traumatic spinal cord injury. Neural Regen Res. 2017;12(5):702-713. DOI: 10.4103/1673-5374.206633.

27. Zhang K, Wang W, Xu M, Frank AJ, Luo J. Role of MCP1 and CCR2 in ethanol-induced neuroinflammation and neurodegeneration in the developing brain. J Neuroinflammation. 2018;15:1-14. DOI: 10.1186/s12974-0181241-2. 
28. Carvalho CAM, Tirapelli DPC, Rodrigues AR, Lizarte Neto FS, Novais PC, Silva JP, Carlotti Junior CG, Colli BO, Tirapelli LF. Morphological and immunohistochemical analysis of apoptosis in the cerebellum of rats subjected to focal cerebral ischemia with or without alcoholism model. Acta Cir Bras. 2016;31(9):629-637. DOI: 10.1590/S0102-865020160090000009.

29. Yoo J, Seo J, Eom J, Hwang D. Enhanced Recovery From Chronic Ischemic Injury by Bone Marrow Cells in a Rat Model of Ischemic Stroke. Cell Transplant. 2015;24(2):167-182. DOI: 10.3727/096368913X674666.

30. Cho DY, Jeun SS. Combination therapy of human boné marrow-derived mesenchymal stem cells and minocycline improves neuronal function in a rat middle cerebral artery occlusion model. Stem Cell Res Ther. 2018;9:111. DOI: 10.1186/s13287-018-1011-1.

31. Heiss WD. The Pathophysiology of Ischemic Stroke Studied by Radionuclide Imaging. J Neurol Neuromed. 2016;1(8):22-28. DOI: 10.29245/2572.942X/2016/8.1087.

32. Shah SZA, Zhao D, Taglialatela G, Khan SH, Hussain T, Dong H, Lai M, Zhou X, Yang L. Early Minocycline and Late FK506 Treatment Improves Survival and Alleviates Neuroinflammation, Neurodegeneration, and Behavioral Deficits in Prion-Infected Hamsters. Neurotherap. 2017;14:463-483. DOI: 10.1007/s13311-016-0500-0.

33. Jalal FY, Yang Y, Thompson JF, Roitbak T, Rosenberg GA. Hypoxia-induced neuroinflammatory white-matter injury reduced by minocycline in SHR/SP. J Cereb Blood Flow Metab. 2015;35(7): 1145-1153. DOI: 10.1038/jcbfm.2015.21.
34. Yang Y, Salayandia VM, Thompson JF, Yang LY, Estrada EY, Yang Y. Attenuation of acute stroke injury in rat brain by minocycline promotes blood-brain barrier remodeling and alternative microglia/ macrophage activation during recovery. J Neuroinflammation. 2015;12:1-15. DOI: $10.1186 / \mathrm{s} 12974-015-0245-4$.

35. Pentón-Rol G, Marin-Prida J, Falcón-Cama V. C-Phycocyanin and Phycocyanobilin as Remyelination Therapies for Enhancing Recovery in Multiple Sclerosis and Ischemic Stroke: A Preclinical Perspective. Behav Sci. 2018;8:1-17. DOI:10.3390/bs8010015.

36. Rahmawati E, Prasetyawan S, Mahdi C, Srihardyastutie A, Adnyana MO, Aulanni'Am A. Potential of Purple Sweet Potato (Ipomoea batatas L) To Increase BDNF Level and VEGF Expression in The Cerebellum of Ischemic Stroke Rats. J Pure App Chem Res. 2018;7(1):4552. DOI: 10.21776/ub.jpacr.2018.007.01.363.

37. Bell MT, Puskas F, Bennett DT, Herson PS, Quillinan N, Fullerton DA, Reece TB. Dexmedetomidine, an a-2a adrenergic agonist, promotes ischemic tolerance in a murine model of spinal cord ischemia-reperfusion. J Thorac Cardiovasc Surg. 2014;147:500-507. DOI: 10.1016/j. jtcvs.2013.07.043

38. Pydyn N, Miękus K, Kotlinowski J. RNaza MCPIP1 jako istotny regulator wewnątrzkomórkowej puli RNA. Postepy Hig Med Dosw. 2018;72:349-357. DOI: 10.5604/01.3001.0011.8255.

39. Mao R, Yang R, Chen X, Harhaj EW, Wang X, Fan Y. Regnase-1, a rapid response ribonuclease regulating inflammation and stress responses. Cell Mol Immunol. 2017;14(5):412-422. DOI: 10.1038/cmi.2016.70. 